\title{
DISABILITY AND BUREAUCRATIC FORMS OF LIFE
}

by Thomas Abrams

This paper employs a hybrid actor-network theory/phenomenological approach to a frequent bother in the lives of disabled persons: bureaucratic forms. I argue that these forms are key sites where disabled personhood emerges, something I examine through the lens of what philosopher Annemarie Mol calls 'ontological politics'. To be disabled is to be entered into the bureaucratic form of life. These forms translate human existence into a categorize-able, transportable and combinable object, to be administered through 'centers of calculation'. Combining Heidegger's fundamental ontology with Latour's theory of paperwork, I suggest that these forms represent disability in terms of 'objective presence', as a mere pre-existing thing, rather than a human way of being. I conclude with suggestions for further phenomenological research that takes embodied difference as its point of departure. 


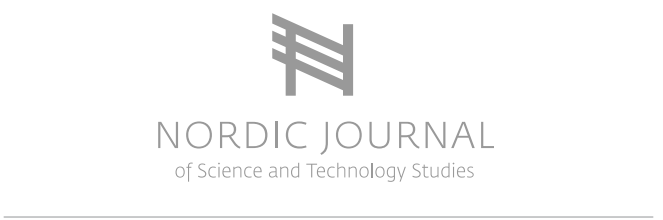

\section{Introduction}

Being disabled requires a lot of paperwork. As if bigotry, poverty and problem architecture weren't trouble enough, filling out bureaucratic forms is an essential part of (Western) disabled existence. Here I want to frame this frequent nuisance as a site of what Annemarie Mol calls 'ontological politics', "a politics that has to do with the way in which problems are framed, bodies are shaped, and lives are pushed and pulled in one way or another" (2002:viii). I do so using two theoretical perspectives: phenomenology and actor-network theory (ANT). ANT helps us ask about the sociomaterial organization of disablement, how it emerges in and through life's passages (Moser \& Law 1999, Winance 2006, Schillmeier 2010). It also gives us a theory of paperwork. Phenomenology helps us ask questions about disabled embodiment, and the experience of its sociomaterial distribution (Toombs 1995, Titchkosky 2011, Abrams 2013). In pursuing this line of questioning, this paper proceeds in

\section{Three Theoretical Traditions}

This section introduces the phenomenological and ANT approaches to disablement. Both of these approaches have been formulated as reactions to the 'social model of disability', an historical materialist model that sees disablement as the outcome of barriers excluding disabled persons (Oliver 1986). The social model is at once an academic model used to study disability, and forms the basis of many policy approaches to disability, emphasizing barrier removal to promote full participation in society (as in the World Health Organization's ICIHD2 definition of disability; see Barnes 2000). A short introduction to the social model will help give us the lay of the land, and highlight the contributions of subsequent work.

Born of 1970s and 1980s UK disability politics, the social model of disability rests on a definitional divide between impairment, biological maladies facing disabled persons, and disability, arbitrary social exclusion faced by those with impairments.' Disability studies as an activist discipline is charged with highlighting the social oppression faced by disabled persons. The historically emergent 'ideology of individualism', reproduced in and through capitalist social relations, causally misattributes exclusion to impairment, when it is in fact oppressive social structures that do the excluding. Capitalism "demanded nothing less than the ideological construction of the individual" (Oliver 1990:44). Medicalization, too, causally misattributes exclusion to problem bodies, not problem social organization: "tragedy theory has served to individualise [sic] the problems of disability and hence to leave social and economic structures untouched" (Oliver 1986:16). Social model disability research is 'emancipatory research' (Barnes 1996, 2003), highlighting

This definition was first made in the Union of Physically Impaired Against Segregation's Fundamental Principles of Disability (hereafter UPIAS; 1975). For an account critical of disability studies' 'year zero' based on the publication of the Principles, see Shakespeare's Disability Rights and Wrongs (2006). three stages. First, I briefly outline the two theoretical traditions introduced above, outlining their common interest in disability and disablement, and their distance from a third approach, the so-called 'social model of disability'. Next, I introduce two different disability forms, the T2201 Disability Tax Credit Certificate (Canada 2012), and the Ontario Disability Support Program application package (Ontario 2012). The impetus for this project was my own experience of being 'filled in' to the T2201. While each form has varying aims and content, together they demonstrate the pervasiveness and the importance of examining the bureaucratic 'form of life' (Wittgenstein 2001a). I conclude this paper discussing the ontological politics of disability and bureaucracy more generally, and establish some questions for further work on disability, its management, and the 'political economy of personhood' more generally (Abrams 2014d).

the oppression faced by disabled persons because of capitalism. It aims to eliminate disability altogether, while impairment is off the sociological agenda.

A particularly good demonstration of the social model comes in Oliver's analysis of the Office of Population and Census Survey's (OPCS) 1986 national disability survey, and his proposed alternatives. Three questions and their alternatives follow.

\section{[Original questions]}

Can you tell me what is wrong with you?

How difficult is it to get about your immediate neighbourhood on your own?

Does your health problem/Disability affect your work in any way at present?

\section{[Alternative questions]}

\section{Can you tell me what is wrong with society?}

What are the environmental constraints which make it difficult for you to get about in your immediate neighbourhood?

Do you have problems at work because of the environment or the physical attributes of others? (Adapted from Oliver 1990:7)

In each case, the social model moves from problem bodies to environmental or attitudinal sources of exclusion. This model is not, of course, without criticism. ${ }^{2}$ What about mental illness: does it fit the disability/impairment rubric? Why must collective organization

\footnotetext{
2 Tom Shakespeare's Disability Rights and Wrongs (2006), for instance, is a refection on a personal journey away from the social model, an approach he previously had defended (1997).
} 
displace discussion of individual impairments? What is the role of non-disabled researchers in all this? These questions are by no means resolved.

In departing from the social model of disability, I am not arguing that it is a useless or antiquated approach to disablement-far from it. Oliver's examination of the OPCS surveys is quite similar to that which I will pursue below. Further, the social model's policy implications are undeniably pertinent to these two cases. Let me be clear: if they are to be of use to disabled persons, all disability forms must understand the problem of extra-personal barriers. But there is surely more to life as a disabled person than the experience of barriers. ${ }^{3}$ By looking to phenomenology and ANT, and recasting disability as a materially-situated way of being-in-theworld, I want to ask how lives get included in governing practices, how disability is made meaningful therein. This does not mean that we cannot ask critical questions about these modes of inclusion, but it does mean that we need to add more voices to the choir. In so doing, I seek to supplement, rather than replace, the social model of disability. The two voices I add will be those of ANT and Phenomenology. I deal with the latter first.

Though they vary in aims and scope, phenomenological approaches to disability emphasize the embodied nature of disability as a mode of existence. They most frequently draw from French phenomenologist Maurice Merleau-Ponty's Phenomenology of Perception (1962). Instead of the clear-cut ontological divide between problem bodies and problem environments, phenomenologists interrogate how the body and world are co-constituted; the body is at once the locus of experience, and a cultural entity. The social model, phenomenologists Hughes and Paterson $(1997,1999)$ argue, cannot account for the lived body (German: Leib), treating it instead as a merely present object (Körper). Mind/body, inside/outside, and self/world-these are cultural distinctions, based on the residual influence of Cartesian mind/body dualism. They do not fully encapsulate what it means to be an embodied, disabled human being-in-the-world.

While Merleau-Ponty is the most frequently cited phenomenologist in the literature, he is not alone. Titchkosky and Michalko (2012) employ Edmund Husserl's (1970) concept of the Lebenswelt, or life-world, to discuss how in mundane existence, disability emerges first as-problem-to-be-solved, always-as-different and always-as-distinct from normal embodiment. They use both Husserl's and Merleau-Ponty's philosophies to ask: "what is the meaning of human embodiment that grounds the unquestioned status of disability as a problem?" (2012:127) Titchkosky's Reading and Writing Disability Differently applies a critical phenomenological perspective to the textual enactment of disability in Canadian government texts and newspaper articles, interrogating how disability is assembled 'in the everyday life of print' (2007:11):

Textuality is one way to accomplish the rendering of disability. To design a disability verification tax credit form; to report a story; to write an account, case or file; to develop a policy on embodied differences: these practices enact the meaning of disability through text. In cultures that assume literacy as a normative value, text becomes a method and a location for the organization, reproduction, and, thereby, enactment, of disability's meanings (2007:28).

Textual representation is not a benign description of things that are 'out there' and already present. It enacts. This textual production is an oriented action, one that can highlight or obscure text producers' underlying aim in reporting facts about disability. ${ }^{4}$ Not only does text obscure its origin, it also obscures that of its objects: 'disabled Canadians' are described in texts outside of the often-lacking material environments in which they dwell. In this way, policy documents depoliticize disability from a problem that we can do something about-to a normal, natural situation outside of oriented human action. Disability is seen as a premade state of marginal existence, rather than an outcome of (often but not always exclusionary) social organization.

Others still use the work of existential phenomenologist Martin Heidegger, to discuss how disability emerges in the course of daily life (Schillmeier 2008, Abrams 2013, 2014b). For Heidegger (1992, 1996), the times-and-spaces closest to human existence (Dasein) are not those of the measuring tape and the clock, but in the 'over there' of the nearby book, and the way we throw ourselves into future tasks (what Heidegger calls moments of care). In medical practice, social service provision, or any other administrative structure, disability is 'enframed', carved from this primordial state of being and brought to presence as an orderable and manageable thing, rather than a state of Dasein (Heidegger 1993). For Heidegger, it is not a divide between the substances of mind and body that is phenomenologically problematic, but rather how things emerge as substances in the first place, as removed from the ontologically prior structures of care. The mind-body problem opposed by the embodied camp is derivative of this more fundamental distinction between the ontology of objective presence and Dasein, what Heidegger calls the 'ontological difference' (1996:211).

Phenomenological approaches to disability differ from the social model's formulation of disability, in that they believe the impairment/disability dichotomy, just like its mind/body cousin, does not accurately represent the cultural production and personal experience of disablement. ANT approaches to disablement, by contrast, take issue with the UPIAS' founding distinction between things

\footnotetext{
4 In this style of thought, clever readers will be able to see Titchkosky's indebted-
} ness to Judith Butler (1993), Dorothy Smith (1990), and Donna Haraway (1994).

\footnotetext{
3 Here I am rejecting the social model's strict divide between disability and impairment. But I think it is possible to reject this ontological divide while still accepting the model's transformative potential for disabled persons.
} 
'natural' and things 'social', in this case disability and impairment.5 In this move, ANT is not picking on emancipatory disability studies in isolation; its theorists oppose any research enterprise that would hypostatize 'the social' as a causal agent. Latour (2004) describes this approach the 'sociology of the social'. ANT, by contrast, follows the emergence of assemblages made of myriad ingredients-some called 'natural', some 'social', some 'human' and finally some 'nonhuman'-that make up our world.

As in the case of phenomenology, I want to emphasize two key themes in my discussion of ANT: disability and text. Moser and Law's classic 'Good Passages, Bad Passages' (1999) redefines disability from a state of permanent inhibition to one of organizational plasticity, depending on the particular passage faced by disabled persons. They follow a woman, Liv, through the passages of her everyday life. Liv's 'ability' or 'disability' is a second-order description of moments when passages are permissible or not. When, for example, a train normally equipped with a lift is without, Liv's disability is made present; her wheelchair is at an impasse.

Dis/ability is about specific passages between equally specific arrays of heterogeneous materials. It is about the character of the materials which en/able those passages. And it is about the arrays which secure or don't secure them-like absent lifts (1999:201).

Here ANT shares the social model's environmental focus, but it does not use the language of social oppression in that task. 'The social' is not the site of Liv's exclusion; it is a description of the material passages where disability is made present, albeit for a fleeing moment. To say, like Oliver, that "disability is a socially constructed category" is not to say very much at all (Hacking 1999). Rather, there are materially situated times and spaces when disability is made present, and those when it is not. Of course, those with standardized body packages experience this less frequently in everyday material environments (something Moser and Law call 'unmarked normativity':208), but this does not detract from

\footnotetext{
5 The best illustration of ANT objections to Oliver's strong social model perspective is Schillmeier's "A Dis/ability Manifesto', chapter three of his Rethinking Disability (2010). In this objection to the social model's nature/society divide, ANT perspectives take a 'strong' social model as their target. There is, of course, varying adherence to such a position in the social model literature: not everyone subscribes to such a hard and fast distinction. Recent social model-inspired work in the geographies of disability, for example, understands space in an equally social and material fashion, while maintaining the social model's emancipatory orientation. See Freund (2001) and Gleeson (1999).
}

\section{Bureaucratic Forms of Life}

The title to this paper is more than simply a bad pun at Wittgenstein's expense. In filling out forms, I want to argue, we participate in the same sort of 'language games' that Wittgenstein describes in his Philosophical Investigations. Departing from the 'picture theory of meaning' and symbolic logic found in the Tractatus Logico-Philosophicus (2001b), Wittgenstein's later work the view of disability as an organizational consequence. In sum, disability "is a set of specificities - which means, to be sure, that we might imagine ourselves as abled, but abled in a million ways. Just as Liv is dis/abled in a million ways" (p. 200).

Born of empirical laboratory studies (Latour \& Woolgar 1979, Latour 1987), ANT has emphasized 'the textual' since its origin. In Laboratory Life (1979), Latour and Woolgar document the process through which nature is inscribed, brought to paper in scientific practice. Science is made possible by 'writing nature' (Asdal \& Ween 2014), by putting to paper the 'trials of strength' where scientific objects are given the opportunity to defy our descriptions of them. In his "Visualization and Cognition" (1986), Latour extends this argument. What is particular about the history of Western science is not a new mind, that "suddenly emerged sometime in the sixteenth century" (p. 1-2) but rather a new way of mobilizing inscriptions. Inscriptions are but one type of what Latour calls 'immutable mobiles', "objects which have the properties of being mobile but also immutable, presentable, readable and combinable with one another" (Latour 1986:7). What is revolutionary about modern science is the circulation of immutable mobiles; a printout, a ledger, a manuscript, or a map-these are stabilized sets of relations moving between multiple 'centers of calculation':

Instead of talking of merchants, princes, scientists, astronomers and engineers as having some sort of relation with one another, it seems to me it would be more productive to talk about 'centers of calculation'. [...] There is not a history of engineers, then a history of capitalists, then one of mathematicians, then one of economists. Rather, there is a single history of these centers of calculation (Latour 1986:32).

Latour's goals were to trace modern history through inscription practices. ${ }^{6}$ This project is extremely ambitious. Mine is not. In what follows, I want to document how disability is shaped through accountability to bureaucratic categories. To be disabled is to be mapped, charted, poked-and-prodded-and then: inscribed. Bureaucratic forms establish passages against which we must read our lives, and the lives of others. They are places where Dasein is delivered to objective presence, where lives are made and remade in materially equipped activity. As I show in the following section, they are places where ANT and phenomenology can work together.

6 Latour (1993) quickly dropped the word 'modern' from his vocabulary.

explores the inseparability of language from practical human activity, situating the production of meaning in shared 'forms of life.'7 In each setting where a bureaucratic form is used, I want to argue,

7 Here I follow a long line of philosophers who would read Wittgenstein phenomenologically. For three examples, see Guignon (1990), Overgaard (2006), and Rorty (1993). 


\section{$\$$}

NORDIC JOURNAL

of Science and Technology Studies

it entrants participate in the production of disability's meaning in a materially equipped fashion, the very stuff of ontological politics. ${ }^{8}$ Following Titchkosky (2007), I suggest each of the forms to follow enacts disability, and in this way is generative rather than representative of 'the real'. The next question: how is reality assembled in Canadian disability forms?

The T2201 Disability Tax Credit Certificate is an obligatory passage point for Canadians to qualify for the disability tax benefits, primarily the Disability Tax Credit, "a non refundable tax credit used to reduce income tax payable on [the successful applicant's] income tax and benefit return" (Canada 2013). The Credit is currently CAD\$7,697 (NOK 44,324.79)9. Additionally, qualification allows disabled persons access to the Registered Disability Savings Plan, where the federal government matches personal savings in a bank account, which can then be invested in long-term securities by the participating financial institution. My objectives here are not to critically examine the Disability Tax Credit's policy implications, but rather to demonstrate how the T2201 translates Dasein into disability-for-tax-purposes. ${ }^{10}$

To be filled out by a qualified medical practitioner," the T2201 marks restriction in seven aspects of daily life: speaking, hearing, walking, elimination (bowel or bladder functions), feeding, dressing and performing the mental functions necessary for everyday life (Canada 2012). 'Vision' falls under its own category, though it is verified like the other aspects. Applicants have two potential avenues for qualification. They either can be 'markedly restricted' in one aspect of daily life, or 'significantly restricted' in two or more aspects, such that they add up to marked restriction. Marked restriction is defined such that:

all or substantially all of the time (at least 90 percent of the time), you are unable or it takes you an inordinate amount of time [three times the normal time to complete the activityAuthor] to perform one or more of the basic activities of daily living [...] even with therapy (other than therapy to support a vital function) and the use of appropriate devices and medication (Canada 2012).

Impairments must also be 'prolonged', they must have "lasted, or is expected to last, for a continuous period of 12 months" (Ibid.). In these criteria, we find the form to be a textbook case of 'medicalization', as per Oliver's (1990) formulation. The doctor performs the

\footnotetext{
8 Here 'entrants' is used both to refer to those participating in formal entry, and the entity so entered. In the T2201 Disability Tax Certificate (Canada 2012) for instance, this involves medical practitioner, applicant and their disability status. 9 Exchanged at 5.7587 NOK to \$1 CAD.

10 For a detailed discussion of tax policy as Canadian social policy, and the Disability Tax Credit's place therein, see Prince (2001). Prince suggests that while tax policy has been a common government instrument to address disability issues, it leaves much to be desired. Uptake is low, the DTC only applies to taxes owed, and schemes like the Medical Expense Tax Credit only reimburse medical expenses paid, failing to attend to the needs of many disabled Canadians and their families. 11 Qualification entails a professional designation related to the impairments at hand. The seven accepted designations: medical doctors, optometrists, audiologists, occupational therapists, physiotherapists, psychologists, and speech-language pathologists.
}

translations of Dasein, and aspects of disabled livelihood that are not within the purview of the medical professional are excluded.12

If this is the extent that the medicalization critique is pursuedand this is the extent to which it is pursued in Oliver's Politics of Disablement-then I am unsatisfied. Mimicking the ANT critique of 'the social,' to say that doctors participate in medicalization is not to say very much. This does little more than establish a 'biomedical boogeyman' (Abrams 2014a:754), an abstract enemy rather than a coherent object of critique. A more satisfying line of thought would document the specific processes by which other modes of existence are excluded or included as medical by professionals so designated. The critique of medicalization is thus reformulated as a project of 'ontological differentiation' (Abrams 2013:46), an empirical documentation of the movement from Dasein to objective presence and back again. What is particularly useful about an empirical documentation of medicalization is this: two processes can both be medicalized, but bring the data to accounts in wildly different ways. The goal should not be to figure out if activities are, in fact, medical or not, but to "catch the work of fact production in flight" (Garfinkel 1967:79), to see how disability is delivered to the purview of medical professionals and to document what is lost in transit. This project is not opposed to Oliver's views on medicalization, but extends his abstract critique to the production and allocation of both disabled and able-bodied personhood.

In the T2201, for example, physical disability is treated as purely somatic malfunction, objective lack possessed by a problem body, rather than as a mode of Dasein disclosed in care. Everyday tasks as translated to purely mechanistic modes of body function rather than as a way of being. Consider restriction in walking.

Your patient is considered markedly restricted in walking if, all or substantially all of the time, he or she is unable or requires an inordinate amount of time to walk even with appropriate therapy, medication, and devices.

\section{$[\ldots]$}

Examples of marked restriction in walking (examples are not exhaustive):

Your patient must always rely on a wheelchair, even for short distances outside the home.

Your patient can walk 100 meters (or approximately one city block) but only taking an inordinate amount of time, stopping because of shortness of breath or because of pain, all or substantially all of the time (9o percent of the time).

Your patient experiences severe episodes of fatigue, ataxia, lack of coordination, and problems with balance. [...] Between episodes, your patient continues to experience the above symptoms, but to a lesser degree. Nevertheless, these

12 The form states: "working, housekeeping, managing a bank account and social or recreational activities are not considered activities of basic living." 


\section{$\$$}

NORDIC JOURNAL

of Science and Technology Studies

symptoms cause him or her an inordinate amount of time to walk, all or substantially all of the time ( $90 \%$ of the time; Canada 2012).

This T2201 translation of walking obliterates the sociomaterial passages where walking is disabled. Are there stairs, snow or inclines on the city blocks where the ideal subject walks with impairment? The form is silent on extra-personal barriers, singly locating marked restriction in the body-as-medical object, and not lived embodiment. This is in line with both Titchkosky's analysis of policy documents, and extends Oliver's critique of the OPCS surveys. Using Heidegger's phenomenology, we can say that the T2201 treats disability as 'objectively present', as a deficient-body-thing, rather than an indivisible mode of human existence. This is further cemented with the '90\% of the time' qualifier (added in the most recent version of the $\mathrm{T2201}$, absent from Canada 2011) implying that disability is ever-present in the applicant's body; the criteria are ignorant to the barriers intentionally avoided by adjustment to the applicant's daily routine. Finally, the form is gendered in that activities performed overwhelmingly by women in Canadian society are absent from the restriction criteria. ${ }^{13}$ In each of these ways, the ontological difference is not simply a philosophical concept; it is manifest in the translation of Dasein into disability via the T2201's assessment criteria.

There are many similarities, but also several differences, in the ontological differentiation performed by the Ontario Disability Support Program's (hereafter ODSP) application package. I will focus on the latter. As a 'sister' program to Ontario Works (social assistance, welfare), the ODSP is responsible for administering social supports, of either the income or employment variety, for disabled persons in Canada's most populous province. As with the T2201, ODSP applicants must meet a 'duration requirement', whereby conditions qualify as disabling so long as they are expected to last one year or more, as stated in the ODSP Act (1997). For our purposes, two components of the ODSP application provide sites for phenomenologically interesting comparison to the kind of medicalization performed by the T2201, the Health Status Report (HSR) and Activities of Daily Living Index (ADL).

The ODSP-HSR is to be completed by a medical practitioner who has treated the applicant. Three definitions are provided for their reference. Condition, "the name of the disease or disease state or diagnosis or syndrome" and the related Impairment, "the loss, loss of use or derangement of any body part or system or function. Function can be psychological or psychiatric in origin." Finally, Restriction "is the limitation to the activities of daily living arising directly or indirectly from the impairment" (Ontario 2012). Condition and impairment are paired in a single two-column section (p.3), the latter caused by the former. In line with the duration requirement, practitioners are instructed to list all applicable conditions, with the exception of those "conditions that have been resolved or are not current or are not ongoing within the last year". To this effect, 'Lung Cancer - Shortness of Breath' are provided as examples. On the following page, Restrictions are divided into three columns: restriction, duration, prognosis; "cannot walk more than 3 blocks before having to stop", "is expected to last one year or more and is continuous," and "is likely to deteriorate" is provided.

The ODSP application provides more than an opportunity for a boring, second hand description of an immutable mobile: it asks that we critically review both the social model's deep-seated impairment/disability dualism and its embodied phenomenological alternative. ${ }^{14}$ In both cases, I want to argue the problem with the ODSP and T2201 forms is not an ontological divide between disability and impairment (or mind and body, or between anything else), but the ontology of objective presence itself. Rather than see the dual or singular terms as representative or as misrepresentative of what disability is or is not, dualism or monism should be seen as an emergent property of materially equipped regimes of calculation. In some regimes, as in the T2201's seven aspects of daily living, disability and impairment are united within the same analytical regime. In the HSR, however, the dualism is maintained in the divide between condition and impairment, on the one hand, and restriction on the other. The important point here is not about the definitive capacity of the disability/impairment dichotomy as a hard and fast definition of disability, but rather the way it treats disability as an objectively present thing and not as a way of human being. United or divided, this ontological basis passes over what it means to be human, what it means to experience disability in everyday life. As above, this passes over the experience of the world of care, its location in social and material environments, and the bad passages that might curtail particular ways of being. That impairment and disability are aligned or distinct does not matter; if we focus on the division between disability and impairment, we miss the problematic, objectively present ontology on which those two terms are predicated.

This is particularly important when we look to restricted mental capacity. Here we can turn to the ADL, required for any successful application, seeking "to describe the impact of the impairment on the applicant's ability to attend to his or her personal care, function in the community and function in the workplace" ( $p$. 12). The index consists of twenty-six questions, and restrictions are ranked from Class 1, "Within normal limits OR not applicable" to Class 4, "Severe or complete limitations on most occasions to completion of the task" (Ibid). I will not list the questions in their entirety here, only those that address mental 'function in the community'. These are:

(1) Orientation to time, person and place.
13 A similar exclusion is found in the Ontario Disability Support Program Employment Supports, where gendered forms of domestic labour are excluded from the type of labour supported by the program; see Abrams (2014C). 14 Recall the social model divides disability into impairment (medical con-
ditions facing individual persons) and disability (as social exclusion). 
(2) Recognizes within normal limits the common dangers in the home, workplace or community.

(3) Ability to comprehend, express or communicate orally.

\section{(4) Use the telephone. [...]}

(6) Exhibits normal limits of functioning with respect to impulse control and behaviour. [...]

(18) Is able to utilize commercial services (banks, hydro, phone company, etc.)

The remaining questions relate to individual function in isolation, and predominantly physical function at that. Here I think it is easy to point to a mind/body dualism, and then wash our hands with the matter. Such a divide certainly exists-we are asking different kind of questions, and getting different answers, about mental things than we are about physical things. This is the same sort of logic underpinning Descartes' substance dualism (see Hacking 2005).
There is a great deal more to this story than a substantive divide between mental and extended substance. By translating mental performance as a rational, brain-bound capacity that those with mental restriction cannot do, the form obliterates the environmental infrastructure that makes those rational capacities possible. The 'problems' encountered in "ability to use commercial services", for instance, places pathological sociomaterial organization solely in the hands of deficient brain states, and obscures the passages necessary for calculation and ability to emerge in the first place (as documented by Schillmeier above). It abstracts from the material passages in which disability is lived in, as care, and instead treats disability as a cause, certainly not an outcome, of moments of incapacity. To repeat, and to conclude this section: to quibble about what kind of substance disability refers to, we overlook the phenomenologically more important point, about the problematic nature of substance ontology more generally. This ontology is enacted in the translation made by the T2201 and ODSP forms, and this is the documentation, Latour's immutable-and-yet-mobile sets of relations, delivered to federal and provincial bureaucratic centers of calculation. To chart the emergence of this ontology in practice and to propose alternatives: this is what Annemarie Mol means by 'ontological politics.'

\section{Bureaucracy and the Political Economy of Personhood}

Before I conclude this paper, some caveats should be made. The first relates to the give-and-take present in the bureaucratic form of life. To suggest that every medical professional uniformly applies either form's criteria to the letter would be ludicrous. The clinical form-encounter is predicated on the following mentality: this person under my assessment is disabled, and I will do what I can to get them the help they need. Of course, every good doctor (like every good bureaucratic form) needs to sort out who deserves attention, and who does not. ${ }^{15}$ Here another Wittgensteinian concept is apt: the 'language game' (2001a). In games like these, some players are more adept than others. There is a grammar to filling out forms, to performing medical diagnosis, and in reporting symptoms so organized. An example: in her brilliant ethnographic work with fibromyalgia (FM) sufferers' groups in Ottawa, Ontario, Wilson (2012) documents how support groups served not only therapeutic goals, but had a bureaucratic orientation as well.

In addition to providing an informal arena for discussion of FM and health related issues [,] the support group organizers had amassed a small collection of educational materials available for loan by the group members. Included in this collection were take-home sheets explaining FM from a sufferer's perspective, FM from a family member's perspective, clinical literature on

15 What constitutes a 'good' doctor is, of course, by no means settled. In the FM case 'good' doctors are ones who believe their patients actually experience symptoms, and are not malingerers or just plain lazy. Though beyond the purview of the present paper, these tacit networks of trust underlying diagnosis, verification and social assistance are worthy of future sociological attention. To this end, I am presently pursuing an analysis of trust networks in Ontario Social Benefit Tribunal decisions, where applicants appeal decisions by the Ministry of Community and Social Services. the syndrome, a large manual on the process of applying for disability [supports], literature on living with FM [... and] experiences with certain physicians and clinics (Wilson 2012:76).

My point is simple: disorders like FM are extremely hard to codify within regimes like those of the T22O1 and the ODSP. In order to qualify for benefits, and even to receive diagnoses, ${ }^{16} \mathrm{FM}$ sufferers have to learn to play the game..$^{17}$ This practice is materially based: FM sufferers set up their own immutable mobiles and centers of calculation to gain access to the provincial and federal government supports they need to live decent lives. This jockeying and negotiation, too, must be seen as part of the bureaucratic form of life.

The ontological politics of FM provides a valuable lesson for improvements to social policy. Not all conditions require the same sorts of negotiation. The ODSP and DTC verification criteria are far more effective at describing permanent physical disability, like the muscular dystrophy for which I was verified, than episodic conditions like FM. And yet, because of the ontological presumptions underlying these two government support systems, all conditions must be judged on the same objectively present rubric. If we were to recast disablement as a process that emerges in particular moments of everyday existence, in Heidegger's 'care', then the bias would be shifted away from the verification of problem bodies to that of problem processes-Mol and Law's 'bad passages'-where disablement emerges. With this said, making the forms' criteria

16 Juuso et al (2011) call this the 'double burden' of living with Fibromylagia.

17 Perhaps 'games' is more apt-strategies in one space might not work well in others. 
task-based would only improve the extent to which they describe the human way of being, as disclosed in embodied and materially situated practice. Focusing solely on application criteria disregards the more fundamental problem of inequality faced by disabled persons in Canadian society, ignored by the federal tax and provincial social assistance systems. Acknowledging this shortcoming, were a more just and effective system to replace the status quo, it would have to overcome the systematic bias against persons with the 'wrong' kinds of disabilities-'wrong' because they cannot be easily inscribed according to the ontology of objective presence.

Finally, a note on the political economy of personhood: I have used this awkward phrase to talk about the social and material conditions in which humans are recognized as such. I use these terms instead of 'subjectivity' for the following reasons. First, subjectivity smacks of a very isolated, disembodied epistemological knower that phenomenologists have sought out to discredit. The epistemological subject-objective world relationship fails to capture the experience of Dasein. Secondly, however awful the phrase may be, the political economy of personhood implies a process. 'Subjectivity' implies a pre-existing state of affairs; we are always subjects capable of experience. In my use, personhood is manufactured, organized, categorized and assembled. None of these regimes can fully capture Dasein-nor should they-but they help to show the way disabled being is enframed in societies organized through bureaucratic activity. It is a first step towards a disabled phenomenology (Abrams 2014d), one that takes human difference

\section{Literature}

Abrams, T. 2013. Being-Towards-Death and Taxes: Heidegger. Disability, and the Ontological Difference. Canadian Journal of Disability Studies 2(1) 28-50.

-- - 2014a. Boon or Bust? Heidegger, Disability Aesthetics and the Thalidomide Memorial. Disability \& Society 29(5), 751-762.

---. 2014b. Flawed by Dasein? Phenomenology Ethnomethodologv and the Personal Experience of Physiotherapv. Human Studies, 37(3), 437-446.

---. 2014C. From Homines Inhabiles to Homo Economicus and Back Again: Michel Callon, Distributed Agency and the Ontario Disability Support Program's Emplovment Supports. Journal of Cultural Economy.

---. (2014d). Is Evervone Upright? Erwin Straus' "The Upright Posture" and Disabled Phenomenology. Human Affairs 24(4), 564-573.

Asdal, K., \& Ween, G. 2014. Writing Nature. Nordic Journal of Science and Technology Studies 2(1), 4-10.

Barnes, C. 1996. Disability and the Myth of the Independent as its point of departure, rather than an abstract, ahistorical and always-able ideal consciousness. Analyzing bureaucratic forms is one small step in this greater journey.

I began this paper complaining about the required paperwork to live as a disabled person, a frequent bother. I began by outlining the social model of disability, which provided a basic analysis of bureaucratic measures. I then turned to two different theoretical perspectives in order to make sense of this, phenomenology and ANT. In phenomenology we were presented a theory and method to analyze existence as a person, in this case, a disabled one. ANT, by contrast, provided both a sociomaterial lens through which to examine disabled livelihood, and a theory of paperwork, tracing the movement of immutable sets of relations between centers of calculation. In the final substantive section of this paper, I looked to two different forms representative of the bureaucratic form of life, the T2201 Disability Tax Credit Certificate, and two components of the ODSP application, the Health Status Report and the Activities of Daily Living Index. In both these regimes of measurement, ability is translated into the ontology of objective presence. This is cause for us to revisit both the social model's impairment-disability dichotomy, and the phenomenological opposition to mind-body dualism. Both of these problems are derivative of the more fundamental problem of the ontological difference. As a whole, the bureaucratic paperwork points us to the realities of living as a disabled person in the West, a small step towards a philosophy that takes embodied difference as its point of departure, rather than its limits.

Researcher. Disability \& Society 11(1) 107-110.

- - . 2000. A working social model? Disability work, and disability politics in the 27st century. Critical Social Policy, 65, 441-457.

- - . 2003. What a Difference a Decade Makes: Reflections on Doing Emancipatory Disability Research. Disability \& Society 18(1), $3-17$.

Butler, J. 1993. Bodies that Matter: On the Discursive Limits of "Sex". London and New York: Routledge.

Canada. 2011. T2201 Disability Tax Credit Certificate. Ottawa: Canada Revenue Agency.

---. 2012. T2201 Disability Tax Credit Certificate. Ottawa: Canada Revenue Agency.

---. 2013. Medical and Disability-Related Information 2013. Ottawa: Canada Revenue Agency.

Freund:2001. Bodies, Disability and Spaces: the social model and disabling spatial organisations. Disability \& Society 16(5), 689-706. 
Garfinkel, H. 1967. Studies in Ethnomethodology. Englewood Cliffs: Prentice-Hall.

Guignon, C. 1990. Philosophy after Wittgenstein and Heidegaer. Philosophy and Phenomenological Research, 50(4), 649-672.

Hacking, I. 1999. The Social Construction of What? Cambridge: Harvard University Press.

- - . 2005. The Cartesian Vision Fulfilled: Analogue Bodies and Digital Minds. Interdisciplinary Science Reviews, 30(2) 153-166.

Haraway, D. 1994. A Game of Cat's Cradle: Science Studies, Feminist Theory, Cultural Studies. Configurations 2(1), 59-71.

Heidegger, M. 1992. The Concept of Time (W. McNeil, Trans.). Oxford: Blackwell.

- - - 1996. Being and Time (J. Stambaugh, Trans.). New York: State University of New York Press.

- - - 1993. The Question Concerning Technology. In D. F. Krell (ed.), Martin Heidegger: Basic Writings (2nd ed., pp. 307-342). San Francisco: Harper Collins.

Hughes, B., \& Paterson, K. 1997. The Social Model of Disability and the Disappearing Body: Towards a Sociology of Impairment. Disability \& Society 12(3), 325-340.

Husserl, E. 1970. The crisis of European sciences and transcendental phenomenology; an introduction to phenomenological philosophy (D. Carr, Trans.). Evanston: Northwestern University Press.

Juuso, Päivi, Skär, L., Olsson, M., \& Söderberg, s. 2011. Living with a double burden: Meanings of pain for women with fibromyalgia. International Journal of Qualitiative Studies of Well-being, 6(3), n.p.

Latour, B. 1986. Visualization and Cognition: Thinking with Eyes and Hands. In H. Kuklick, \& E. Long (Eds.), Knowledge and Society: Studies in the Sociology of Culture Past and Present, 1-4O. London: JAI Press.

- - - 1987. Science in Action: How to Follow Scientists and Engineers Through Society. Cambridge: Harvard University Press.

---. 1993. We Have Never Been Modern (C. Porter, Trans.). Cambridge: Harvard University Press.

---. 2004. Reassembling the Social: An Introduction to ActorNetwork Theory. New York: Oxford University Press.

Latour, B., \& Woolgar, S. 1979. Laboratory Life: The Social Construction of Scientific Facts. Beverly Hills and London: Sage.

Merleau-Ponty, M. 1962. Phenomenology of Perception (C. Smith,
Trans.). New York: Routledge.

Mol, A. 2002. The Body Multiple: Ontology in Medical Practice. Durham: Duke University Press.

Moser, I., \& Law, J. 1999. Good Passages, Bad Passages. In J. Law, \& J. Hassard (eds.), Actor-Network Theory and After, 196-219. Oxford: Blackwell.

Oliver, M. 1986. Social Policy and Disability: Some Theoretical Issues. Disability, Handicap \& Society 1(1), 5-17.

- - . 1990. The Politics of Disablement. London: MacMillan.

Ontario. 2012. Ontario Disability Support Program Application Package. Ministry of Community and Social Services.

Overgaard, S. 2006. The problem of other minds: Wittgenstein's Phenomenological perspective. Phenomenology and the Cognitive Sciences, 5(1), 53-73.

Paterson, K., \& Hughes, B. 1999. Disability Studies and Phenomenology: the Carnal Politics of Everyday Life. Disability \& Society 14(5), 597-610.

Rorty, R. 1993. Heidegger and Wittgenstein on the Reification of Language. In C. Guignon (ed.), The Cambridge Companion to Heidegger, 337-357. Cambridge: Cambridge University Press.

Schillmeier, M. 2008. Time-Spaces of $\mathrm{In} /$ dependence and Dis/ ability. Time and Society 17(2/3) 215-231.

---. 2010. Rethinking Disability: Bodies, Senses, Things. New York: Routledge.

Shakespeare, T. 2006. Disability Rights and Wrongs. London: Routledge.

Shakespeare, T., \& Watson, N. 1997. Defending the Social Model. Disability \& Society 12(2) 293-300.

Smith, D. 1990. The Conceptual Practices of Power: A Feminist Sociology of Knowlegde. Toronto: University of Toronto Press.

Titchkosky, T. 2007. Reading and Writing Disability Differently: The Textured Life of Embodiment. Toronto: University of Toronto Press.

---. 2011. The Question of Access: Disability, Space, Meaning. Toronto: University of Toronto Press.

Titchkosky, T., \& Michalko, R. 2012. The Body as The Problem of Individuality: A Phenomenological Disability Studies Approach. In D. Goodley, B. Hughes, \& L. Davis (eds.), Disability and Social Theory: New Directions and Developments, 127-142. Houndmills, Basingstoke, Hampshire: Palgrave Macmillan. 
Toombs, S. K. 1995. The Lived Experience of Disability. Human Studies $18,9-23$.

Wilson, A. 2012. The dvs-appearing bodv: understanding the lived experience of women with fibromylagia. Carleton University, Ottawa.

Winance, M. 2006. Trving out the wheelchair: the mutual shaping of_people and devices through adjustment. Science, Technology \& Human Values, 31(1), 52-72.

Wittgenstein, L. 2001a. Philosophical Investigations (G. E. M. Anscombe, Trans.). Oxford: Blackwell.

---. 2001b. Tractatus Logico-Philosophicus (D. F. Pears, \& B. F. McGuinness, Trans.). New York: Routledge. 